Research Paper

\title{
The effects of a prior malignancy on the survival of patients with ovarian cancer: a population-based study
}

\author{
Xiaoyuan Bian 1,2, Jiafeng Xia ${ }^{1,2}$, Kaicen Wang 1,2, Qiangqiang Wang 1,2, Liya Yang 1,2, Wenrui Wu 1,2, and \\ Lanjuan $\mathrm{Li}^{1,2}$ \\ 1. State Key Laboratory for Diagnosis and Treatment of Infectious Disease, National Clinical Research Center for Infectious Diseases, The First Affiliated \\ Hospital, Zhejiang University, Hangzhou, P. R. China. \\ 2. Collaborative Innovation Center for Diagnosis and Treatment of Infectious Diseases, Hangzhou, P. R. China
}

$\square$ Corresponding author: State Key Laboratory for Diagnosis and Treatment of Infectious Disease, The First Affiliated Hospital, Zhejiang University, Hangzhou 310003, P. R. China. Tel.: +86-571-8723-6458; Fax: +86-571-8723-6459; E-mail: ljli@zju.edu.cn.

(c) The author(s). This is an open access article distributed under the terms of the Creative Commons Attribution License (https://creativecommons.org/licenses/by/4.0/). See http://ivyspring.com/terms for full terms and conditions.

Received: 2020.04.01; Accepted: 2020.08.13; Published: 2020.08.25

\begin{abstract}
Background: With the improvement in the prognostic outcomes of multiple malignancies, the population of cancer survivors is growing rapidly and is at higher risk of developing secondary ovarian cancer. However, the prevalence and clinical outcomes of prior cancer among newly diagnosed ovarian cancer patients remain unknown.

Methods: Patients diagnosed with ovarian cancer between 2004 and 2015 were identified using the Surveillance, Epidemiology, and End Results database. Patients were divided into two groups based on whether there was a prior malignancy. A multivariate Cox regression analysis was used to calculate all-cause and ovarian-specific survival. Furthermore, we conducted subgroup survival analyses of patients stratified by previous cancer site to explore the associations between prior cancer site and survival outcomes.

Results: A total of 52,182 patients with primary ovarian cancer were identified, and $3.6 \%(n=1,860)$ had a documented prior malignancy. In multivariate analyses, patients with prior malignancies had a worse all-cause and ovarian cancer-specific prognosis than those without. In subset analyses, patients with a history of thyroid cancer had a better all-cause and ovarian cancer-specific prognosis, and patients with prior colorectal, urinary system, skin, lung, haematologic and stomach cancers were at risk of decreased survival compared to that of patients without a prior cancer.

Conclusions: Prior malignancy has an adverse impact on the survival of patients with ovarian cancer, and the impact on prognostic outcomes varies by different prior cancer sites. The inconsistent survival effects of previous malignancies should be considered in clinical trial design and recruitment.
\end{abstract}

Key words: Ovarian cancer; SEER; Prior malignancy; prognosis

\section{Introduction}

In the United States of America, ovarian cancer remains one of the most common tumours and the fifth most common cause of death in females according to 2020 cancer statistics [1]. There have been many studies regarding the detection and therapy of ovarian cancer, but little is known about the clinical and prognostic factors of ovarian cancer as a second malignancy.

With the improvement in early diagnosis and better treatments, much progress has been made in the prognostic outcomes of multiple malignancies. The number of cancer survivors is increasing annually and is expected to reach approximately 20 million by $2026[2,3]$. Studies have demonstrated that better survival expectations increase the possibility of developing a second primary malignancy among survivors of cancers [4-7], including ovarian cancer. Nearly $25 \%$ of elderly and $10 \%$ of younger cancer patients have had a pre-existing malignancy [8], and a higher risk of developing a second ovarian cancer has 
been observed in cancer survivors [9]. Thus, there is a pressing need to understand the clinical characteristics and survival outcomes of these populations.

Recently, patients with prior malignancies were commonly excluded from most clinical trials due to the concern that a prior malignancy diagnosis would interfere with the implementation and efficiency of the treatment [10]. A similar trend was observed in ovarian cancer trials in which a prior cancer was adopted as an exclusion criterion [11-13]. However, the reasonableness of the exclusion criteria has barely been assessed, and evidence-based guidelines are urgently needed. Previous research has indicated that a history of malignancy does not result in an inferior prognosis of lung cancer, the effects vary by different prior cancer types and stages [10, 14, 15], and the validity of the criteria has not been evaluated in ovarian cancer patients. We therefore assessed the prevalence and clinical outcomes of prior cancer among newly diagnosed ovarian cancer patients by using the Surveillance, Epidemiology, and End Results (SEER) database.

\section{Methods}

\section{Data Source}

All data of patients with primary ovarian cancer were obtained from the SEER database, which is a population-based cancer database maintained by the National Cancer Institute. SEER*Stat (version 8.3.6) software was used to acquire the cohort based on SEER 18 Regs Custom Data (with additional treatment fields), Nov 2018 Sub (1975-2016 varying). This study was exempt from institutional review because the data were open-access and deidentified.

\section{Patients}

In the present study, the cohort included women ( $\geq 18$ years old) diagnosed with primary ovarian cancer (Site Recode ICD-O-3/WHO 2008 C56.9) between 2004 and 2015. Patients who were diagnosed based only on autopsy or death certificates or without information of active follow-up, survival months or previous malignancy status were excluded. In addition, patients with more than one prior cancer were also excluded. Records for prior malignancy, survival months, age at diagnosis, year of diagnosis, race, CA-125, histologic type, tumour size, AJCC stage (6th), tumour grade, insurance coverage, marital status, surgery, radiation and chemotherapy were obtained using the dataset.

Patient cases were divided into two groups based on whether there was a prior malignancy or not. We also excluded patients with a history of ovarian cancer to avoid the possibility of synchronous malignancy. In addition, we selected cases whose ovarian malignancy was diagnosed between 6 and 60 months following the diagnosis time of the first malignancy. Six-month exclusion was adopted to avoid the influence of synchronous primary cancers, and 60-month exclusion was a common exclusion criterion in clinical trials $[10,16]$. Next, patients with prior cancer were subdivided into groups according to the prior malignancy site as follows: breast, colon and rectum, uteri, urinary system, lung, skin, thyroid, haematologic, stomach, liver, other gastrointestinal and genitourinary, and other cancers.

\section{Statistical Analyses}

Descriptive statistics were conducted to compare the baseline characteristics of the included ovarian patients with and without a previous malignancy. The distributions of prior tumour sites and mean interval times between previous cancer and ovarian cancer were calculated. Survival time was calculated from the time of ovarian cancer diagnosis to the last follow-up or death from any cause. Next, we adopted Kaplan-Meier survival curves of ovarian patients with and without prior cancer and conducted log-rank tests to estimate and compare the survival differences. In addition, we conducted nomograms to estimate the survival outcomes using $\mathrm{R}$ software. The $\mathrm{C}$-index was used to measure the discrimination, and calibration plots were used to evaluate the predicted and actual probabilities. A multivariate Cox regression analysis of all-cause and ovarian-specific survival was conducted to estimate the prognostic effect of a prior malignancy after adjusting for variates, including age, race, CA-125, histologic type, tumour size, AJCC stage, tumour grade, insurance coverage, marital status and therapies. Furthermore, we conducted subgroup survival analyses of patients stratified by previous cancer site to explore the associations between the prior cancer site and survival outcomes. SPSS (version 20.0), GraphPad Prism (version 7.0) and $\mathrm{R}$ software (version 2.15.3) were used to conduct statistical analyses and images. A two-tailed P value of less than 0.05 was considered significant.

\section{Results}

In the present study, we identified 52,182 patients with primary ovarian cancer diagnosed between 2004 and 2015. Among this cohort of patients, $3.6 \%(\mathrm{n}=1,860)$ had a documented prior malignancy. In contrast to the cases without previous malignancies, patients with prior cancer were older (>65 years, $52.5 \%$ vs. $39.7 \%, \mathrm{P}<0.001$ ), were white ( $84.1 \%$ vs. $82.0 \%, P=0.002)$, had a smaller tumour size $(24.5 \%$ vs. $19.7 \%, \mathrm{P}<0.001)$, had fewer epithelial histologic types $(64.9 \%$ vs. $67.1 \%, \mathrm{P}<0.001)$, were less 
likely to show elevated CA- 125 levels ( $57 \%$ vs. $66.4 \%$, $\mathrm{P}<0.001)$ and enjoyed more insurance protection (71.4\% vs. $71.3 \%, \mathrm{P}=0.002)$. Regarding the therapeutic options, patients with prior cancer received less surgery therapy and chemotherapy $(75.2 \%$ vs. $79.5 \%$, $\mathrm{P}<0.001 ; 61.0 \%$ vs. $67.7 \%, \mathrm{P}<0.001)$, and the administration of radiation therapy was similar between patients with and without a prior malignancy $(1.3 \%$ vs. $1.0 \%, P=0.129)$. Additional clinicopathologic characteristics of the included patients are summarized in Table 1.

Table 1. Baseline characteristics of included patients with ovarian cancer $(n=52,182)$

\begin{tabular}{|c|c|c|c|c|c|c|}
\hline \multirow{2}{*}{$\begin{array}{l}\text { Patient } \\
\text { Characteristics } \\
\text { Age at diagnosis }\end{array}$} & \multirow[t]{2}{*}{$\begin{array}{l}\text { Total } \\
\mathrm{N}=52,182\end{array}$} & \multicolumn{2}{|c|}{$\begin{array}{l}\text { With previous } \\
\text { malignancy } \\
\mathrm{N}=1,860(3.6 \%)\end{array}$} & \multicolumn{2}{|c|}{$\begin{array}{l}\text { No previous } \\
\text { malignancy } \\
\mathrm{N}=50,322(96.4 \%)\end{array}$} & $p$ \\
\hline & & & & & & $<0.001$ \\
\hline $18-40$ & & 65 & $(3.5 \%)$ & $4,298(\varepsilon$ & & \\
\hline $41-65$ & & 818 & $(44.0 \%)$ & 26,071 & $1.8 \%)$ & \\
\hline$>65$ & & 977 & $(52.5 \%)$ & 1,938 & $7 \%)$ & \\
\hline Year of diagnosis & & & & & & 0.887 \\
\hline 2004-2009 & & 912 & $(49.0 \%)$ & 24,589 & $(48.9 \%)$ & \\
\hline 2010-2015 & & 948 & $(51.0 \%)$ & 25,733 & $(51.1 \%)$ & \\
\hline Race & & & & & & 0.002 \\
\hline White & & 1,565 & $(84.1 \%)$ & 41,268 & $(82.0 \%)$ & \\
\hline Black & & 156 & $(8.4 \%)$ & 4,260 & $(8.5 \%)$ & \\
\hline $\mathrm{AI} / \mathrm{AN}$ & & 15 & $(0.8 \%)$ & 341 & $(0.7 \%)$ & \\
\hline $\mathrm{AP}$ & & 124 & $(6.7 \%)$ & 4,220 & $(8.4 \%)$ & \\
\hline Unknown & & 0 & $(0.0 \%)$ & 233 & $(0.5 \%)$ & \\
\hline CA-125 & & & & & & $<0.001$ \\
\hline Elevated & & 1,061 & $(57.0 \%)$ & 33,437 & $(66.4 \%)$ & \\
\hline Normal & & 182 & $(9.8 \%)$ & 4,183 & $(8.3 \%)$ & \\
\hline Unknown & & 617 & $(33.2 \%)$ & 12,702 & $(25.2 \%)$ & \\
\hline Histologic Type & & & & & & $<0.001$ \\
\hline Epithelial & & 1,207 & $(64.9 \%)$ & 33,758 & $(67.1 \%)$ & \\
\hline Sex-cord-stromal & & 25 & $(1.3 \%)$ & 970 & $(1.9 \%)$ & \\
\hline Germ-cell & & 4 & $(0.2 \%)$ & 1,061 & $(2.1 \%)$ & \\
\hline Others & & 624 & $(33.5 \%)$ & 14,533 & $(28.9 \%)$ & \\
\hline Tumour Size & & & & & & $<0.001$ \\
\hline $0-1 \mathrm{~mm}$ & & 77 & $(4.1 \%)$ & 1,713 & $(3.4 \%)$ & \\
\hline $1-5 \mathrm{~mm}$ & & 254 & $(13.7 \%)$ & 5,680 & $(11.3 \%)$ & \\
\hline $5-10 \mathrm{~mm}$ & & 382 & $(20.5 \%)$ & 9,770 & $(19.4 \%)$ & \\
\hline $10-20 \mathrm{~mm}$ & & 367 & $(19.7 \%)$ & 12,343 & $(24.5 \%)$ & \\
\hline$>20 \mathrm{~mm}$ & & 69 & $(3.7 \%)$ & 3,051 & $(6.1 \%)$ & \\
\hline Unknown & & 711 & $(38.2 \%)$ & 17,765 & $(35.3 \%)$ & \\
\hline AJCC stage (6th) & & & & & & $<0.001$ \\
\hline I & & 373 & $(20.1 \%)$ & 10,494 & $(20.9 \%)$ & \\
\hline II & & 166 & $(8.9 \%)$ & 3,575 & $(7.1 \%)$ & \\
\hline III & & 475 & $(25.5 \%)$ & 14,221 & $(28.3 \%)$ & \\
\hline IV & & 476 & $(25.6 \%)$ & 13,740 & $(27.3 \%)$ & \\
\hline Others & & 370 & $(19.9 \%)$ & 8,292 & $(16.5 \%)$ & \\
\hline Grade & & & & & & 0.310 \\
\hline I & & 109 & $(5.9 \%)$ & 3,236 & $(6.4 \%)$ & \\
\hline II & & 193 & $(10.4 \%)$ & 5,692 & $(11.3 \%)$ & \\
\hline III & & 554 & $(29.8 \%)$ & 15,435 & $(30.7 \%)$ & \\
\hline IV & & 331 & $(16.7 \%)$ & 8,112 & $(16.1 \%)$ & \\
\hline $\mathrm{V}$ & & 693 & $(37.3 \%)$ & 17,847 & $(35.5 \%)$ & \\
\hline Surgery & & & & & & $<0.001$ \\
\hline Yes & & 1,399 & $(75.2 \%)$ & 40,023 & $(79.5 \%)$ & \\
\hline No & & 452 & $(24.3 \%)$ & 9,976 & $(19.8 \%)$ & \\
\hline Unknown & & 9 & $(0.5 \%)$ & 323 & $(0.6 \%)$ & \\
\hline Radiation & & & & & & 0.129 \\
\hline Yes & & 25 & $(1.3 \%)$ & 496 & $(1.0 \%)$ & \\
\hline No & & 1,833 & $(98.5 \%)$ & 49,805 & $(99.0 \%)$ & \\
\hline Unknown & & 2 & $(0.1 \%)$ & 21 & $(0.0 \%)$ & \\
\hline Chemotherapy & & & & & & $<0.001$ \\
\hline Yes & & 1,134 & $(61.0 \%)$ & 34,070 & $(67.7 \%)$ & \\
\hline No/Unknown & & 726 & $(39.0 \%)$ & 16,252 & $(32.3 \%)$ & \\
\hline
\end{tabular}

\begin{tabular}{|c|c|c|c|c|c|c|}
\hline $\begin{array}{l}\text { Patient } \\
\text { Characteristics } \\
\text { Insurance }\end{array}$ & $\begin{array}{l}\text { Total } \\
\mathrm{N}=52,182\end{array}$ & \multicolumn{2}{|c|}{$\begin{array}{l}\text { With previous } \\
\text { malignancy } \\
N=1,860(3.6 \%)\end{array}$} & \multicolumn{2}{|c|}{$\begin{array}{l}\text { No previous } \\
\text { malignancy } \\
\mathrm{N}=50,322(96.4 \%)\end{array}$} & $p$ \\
\hline Yes & & 1,328 & $(71.4 \%)$ & 35,881 & $(71.3 \%)$ & \\
\hline No & & 32 & $(1.7 \%)$ & 1,553 & $(3.1 \%)$ & \\
\hline Unknown & & 500 & $(26.9 \%)$ & 12,888 & $(25.6 \%)$ & \\
\hline Marital status & & & & & & 0.756 \\
\hline Married & & 901 & $(48.4 \%)$ & 24,767 & $(49.2 \%)$ & \\
\hline Unmarried & & 874 & $(47.0 \%)$ & 23,373 & $(46.4 \%)$ & \\
\hline Unknown & & 85 & $(4.6 \%)$ & 2,182 & $(4.3 \%)$ & \\
\hline
\end{tabular}

Abbreviation: AI/AN, American Indian/Alaska Native; AP, Asian or Pacific Islander; CA-125, Cancer Antigen 125; Grade: I, well differentiated; II, moderately differentiated; III, poorly differentiated; IV, undifferentiated; V, unknown.

Among the 1,860 individuals with a previous malignancy, the breast $(46.13 \%)$ was the most common prior cancer site, followed by the colon and rectum $(8.92 \%)$, uterine $(8.82 \%)$, urinary system $(5.75 \%)$, skin $(5.64 \%)$, lung $(5.59 \%)$, thyroid $(4.19 \%)$, haematologic system $(3.12 \%)$, stomach $(0.91 \%)$ and liver $(0.38 \%)$ (Figure 1$)$. As shown in Figure 2, the median interval from the first malignancy to the subsequent ovarian cancer was 29 months, ranging from 20 months (liver) to 34.5 months (colon and rectum).

Next, we conducted a Kaplan-Meier analysis to investigate the impact of prior malignancy on prognosis in patients with ovarian cancer. Significant differences were observed in both all-cause and ovarian cancer-specific survival rates between patients with and without prior malignancy (Both log rank $\mathrm{P}<0.001$, Figure 3). The 3-year and 5-year all-cause survival rates of ovarian patients with prior malignancy were $49.0 \%$ and $35.1 \%$, respectively, and those without prior malignancy were $55.4 \%$ and $43.2 \%$, respectively (Table 2 ). When stratified by previous malignancy sites, patients with a history of breast, uteri and thyroid cancer had a better survival rate than those without prior malignancy, while patients with other types of prior malignancy had a worse survival (Table 2). We further adopted a prognostic nomogram to integrate all independent factors for all-cause and ovarian cancer-specific survival (Figures 4 and 5). The C-index of all-cause and ovarian cancer-specific prediction was 0.771 and 0.776 , respectively (data not shown). The calibration plots of 3-year and 5-year survival are displayed in Figure S1 and S2, which showed optimal concordances between the predicted observations and actual outcomes.

The multivariate Cox regression analysis of the included patients is displayed in Table 3. Patients with a prior malignancy were associated with a worse all-cause and ovarian cancer-specific prognosis by contrast to those without, after adjusting for other variables such as age, race, CA-125, histologic type, tumour size, AJCC stage, tumour grade, insurance coverage, marital status and therapy options 
$(\mathrm{HR}=0.92,95 \% \mathrm{CI}=0.87-0.97, \mathrm{P}=0.003$ and $\mathrm{HR}=0.83$, $95 \% \mathrm{CI}=0.78-0.88, \mathrm{P}<0.001)$. When compared to the individuals without a prior malignancy, patients with a history of thyroid cancer appeared to have a better all-cause and ovarian cancer-specific prognosis (Table 4). In contrast, compared to patients without a prior malignancy, patients with prior colon and rectum, urinary system, skin, lung, haematologic and stomach cancers were at a risk of decreased survival (Table 4).

Table 2. 3-year and 5-year all-cause survival rate of ovarian cancer patients stratified by previous cancer site.

\begin{tabular}{lll}
\hline Previous cancer site & All-cause survival rate & \\
\hline & 3 -year $(95 \% \mathrm{CI})$ & 5 -year $(95 \% \mathrm{CI})$ \\
No previous malignancy & $55.4 \%(55.2 \%, 55.6 \%)$ & $43.2 \%(43.0 \%, 43.4 \%)$ \\
With previous malignancy & $49.0 \%(47.8 \%, 50.2 \%)$ & $35.1 \%(33.9 \%, 36.3 \%)$ \\
Breast cancer & $57.0 \%(55.3 \%, 58.7 \%)$ & $41.5 \%(39.7 \%, 43.3 \%)$ \\
Colon and rectum cancer & $37.6 \%(33.7 \%, 41.5 \%)$ & $21.1 \%(17.5 \%, 24.7 \%)$ \\
Uterine cancer & $56.6 \%(52.2 \%, 61.0 \%)$ & $48.9 \%(44.2 \%, 53.6 \%)$ \\
Urinary system cancer & $43.4 \%(38.4 \%, 48.4 \%)$ & $26.6 \%(21.8 \%, 31.4 \%)$ \\
Skin cancer & $49.3 \%(44.2 \%, 54.4 \%)$ & $32.1 \%(26.9 \%, 37.3 \%)$ \\
Lung cancer & $30.0 \%(25.2 \%, 34.8 \%)$ & $17.5 \%(13.2 \%, 21.8 \%)$ \\
Thyroid cancer & $65.8 \%(60.2 \%, 71.4 \%)$ & $58.3 \%(62.2 \%, 64.4 \%)$ \\
Haematologic cancer & $18.7 \%(13.3 \%, 24.1 \%)$ & $10.4 \%(6.1 \%, 14.7 \%)$ \\
Other cancer & $39.4 \%(35.5 \%, 43.3 \%)$ & $26.7 \%(22.9 \%, 30.5 \%)$ \\
\hline
\end{tabular}

Table 3. Multivariable Cox regression analysis of all-caused and ovarian cancer-specific survival in patients with ovarian cancer.

\begin{tabular}{|c|c|c|c|c|}
\hline Characteristics & $\begin{array}{l}\text { All-cause } \\
\text { adjusted HR }\end{array}$ & $\mathbf{P}$ & $\begin{array}{l}\text { OC-specific } \\
\text { adjusted HR }\end{array}$ & $\mathbf{P}$ \\
\hline \multicolumn{5}{|c|}{ Previous malignancy } \\
\hline Yes & Reference & & Reference & \\
\hline No & $0.92(0.87,0.97)$ & 0.003 & $0.83(0.78,0.88)$ & $<0.001$ \\
\hline Age at diagnosis & & $<0.001$ & & $<0.001$ \\
\hline $18-40$ & Reference & & Reference & \\
\hline $41-65$ & $1.54(1.44,1.65)$ & $<0.001$ & $1.47(1.37,1.58)$ & $<0.001$ \\
\hline$>65$ & $1.15(1.12,1.19)$ & $<0.001$ & $2.13(1.99,2.29)$ & $<0.001$ \\
\hline Race & & $<0.001$ & & $<0.001$ \\
\hline White & Reference & & Reference & \\
\hline Black & $1.18(1.14,1.23)$ & $<0.001$ & $1.16(1.11,1.21)$ & $<0.001$ \\
\hline $\mathrm{AI} / \mathrm{AN}$ & $1.10(0.96,1.26)$ & 0.177 & $1.08(0.94,1.25)$ & 0.292 \\
\hline $\mathrm{AP}$ & $0.93(0.88,0.97)$ & 0.001 & $0.91(0.86,0.95)$ & $<0.001$ \\
\hline Unknown & $0.25(0.18,0.35)$ & $<0.001$ & $0.24(0.17,0.35)$ & $<0.001$ \\
\hline CA-125 & & $<0.001$ & & $<0.001$ \\
\hline Elevated & Reference & & Reference & \\
\hline Normal & $0.61(0.58,0.65)$ & $<0.001$ & $0.61(0.57,0.65)$ & $<0.001$ \\
\hline Unknown & $0.82(0.80,0.84)$ & $<0.001$ & $0.81(0.79,0.84)$ & $<0.001$ \\
\hline Histologic Type & & $<0.001$ & & $<0.001$ \\
\hline Epithelial & Reference & & Reference & \\
\hline Sex-cord-stromal & $0.41(0.35,0.48)$ & $<0.001$ & $0.37(0.31,0.44)$ & $<0.001$ \\
\hline Germ-cell & $0.32(0.25,0.40)$ & $<0.001$ & $0.28(0.22,0.37)$ & $<0.001$ \\
\hline Others & $1.15(1.12,1.18)$ & $<0.001$ & $1.16(1.12,1.19)$ & $<0.001$ \\
\hline Tumour Size & & $<0.001$ & & $<0.001$ \\
\hline $0-1 \mathrm{~mm}$ & Reference & & Reference & \\
\hline $1-5 \mathrm{~mm}$ & $1.40(1.29,1.52)$ & $<0.001$ & $1.40(1.29,1.53)$ & $<0.001$ \\
\hline $5-10 \mathrm{~mm}$ & $1.33(1.23,1.44)$ & $<0.001$ & $1.32(1.21,1.43)$ & $<0.001$ \\
\hline $10-20 \mathrm{~mm}$ & $1.28(1.19,1.39)$ & $<0.001$ & $1.28(1.17,1.39)$ & $<0.001$ \\
\hline$>20 \mathrm{~mm}$ & $1.50(1.36,1.65)$ & $<0.001$ & $1.46(1.32,1.62)$ & $<0.001$ \\
\hline Unknown & $1.43(1.33,1.54)$ & $<0.001$ & $1.43(1.33,1.32)$ & $<0.001$ \\
\hline AJCC stage (6th) & & $<0.001$ & & $<0.001$ \\
\hline I & Reference & & Reference & \\
\hline II & $2.10(1.95,2.26)$ & $<0.001$ & $2.46(2.26,2.67)$ & $<0.001$ \\
\hline III & $4.32(4.09,4.57)$ & $<0.001$ & $5.40(5.07,5.76)$ & $<0.001$ \\
\hline IV & $5.94(5.62,6.29)$ & $<0.001$ & $7.53(7.06,8.04)$ & $<0.001$ \\
\hline Others & $4.46(4.21,4.21)$ & $<0.001$ & $5.54(5.18,5.91)$ & $<0.001$ \\
\hline Grade & & $<0.001$ & & $<0.001$ \\
\hline I & Reference & & Reference & \\
\hline
\end{tabular}

\begin{tabular}{|c|c|c|c|c|}
\hline Characteristics & $\begin{array}{l}\text { All-cause } \\
\text { adjusted HR }\end{array}$ & $\mathbf{P}$ & $\begin{array}{l}\text { OC-specific } \\
\text { adjusted HR }\end{array}$ & $\mathbf{P}$ \\
\hline II & $1.82(1.66,1.99)$ & $<0.001$ & $1.99(1.80,2.21)$ & $<0.001$ \\
\hline III & $2.18(2.00,2.37)$ & $<0.001$ & $2.43(2.21,2.68)$ & $<0.001$ \\
\hline IV & $2.15(1.97,2.35)$ & $<0.001$ & $2.40(2.17,2.65)$ & $<0.001$ \\
\hline $\mathrm{V}$ & $1.95(1.79,2.12)$ & $<0.001$ & $2.17(1.97,2.39)$ & $<0.001$ \\
\hline Surgery & & $<0.001$ & & $<0.001$ \\
\hline Yes & Reference & & Reference & \\
\hline No & $2.91(2.81,3.02)$ & $<0.001$ & $2.92(2.81,3.03)$ & $<0.001$ \\
\hline Unknown & $1.53(1.35,1.74)$ & $<0.001$ & $1.51(1.32,1.73)$ & $<0.001$ \\
\hline Radiation & & $<0.001$ & & $<0.001$ \\
\hline Yes & Reference & & Reference & \\
\hline No & $0.76(0.68,0.84)$ & $<0.001$ & $0.76(0.68,0.85)$ & $<0.001$ \\
\hline Unknown & $0.50(0.28,0.89)$ & 0.018 & $0.45(0.24,0.86)$ & 0.014 \\
\hline \multicolumn{5}{|l|}{ Chemotherapy } \\
\hline Yes & Reference & & Reference & \\
\hline No/Unknown & $1.65(1.61,1.70)$ & $<0.001$ & $1.61(1.56,1.65)$ & $<0.001$ \\
\hline Insurance & & $<0.001$ & & $<0.001$ \\
\hline Yes & Reference & & Reference & \\
\hline No & $1.12(1.04,1.21)$ & 0.002 & $1.11(1.03,1.20)$ & 0.007 \\
\hline Unknown & $1.06(1.04,1.09)$ & $<0.001$ & $1.07(1.04,1.10)$ & $<0.001$ \\
\hline Marital status & & $<0.001$ & & $<0.001$ \\
\hline Married & Reference & & Reference & \\
\hline Unmarried & $1.16(1.14,1.19)$ & $<0.001$ & $1.14(1.11,1.17)$ & $<0.001$ \\
\hline Unknown & $0.92(0.87,0.98)$ & 0.006 & $0.88(0.82,0.93)$ & $<0.001$ \\
\hline
\end{tabular}

\section{Discussion}

An increase in cancer survivors has recently been observed due to advances in diagnostic and treatment strategies. With prolonged survival, patients are more likely to be subsequently diagnosed with a second primary malignancy. Determining the clinical significance and survival outcomes of prior malignancies is of great importance, as these factors might affect clinical trial design, oncological practice and therapeutic decisions. However, few studies have focused on patients with ovarian cancer who have a prior history of cancer.

In our large population-based study, we evaluated the effect of previous malignancies on the clinical characteristics and prognosis of patients with ovarian cancer. In our cohort, approximately $3.6 \%$ of patients had a documented prior malignancy within 5 years of the initial ovarian cancer diagnosis. Consistent with the results of previous studies [8,17], a higher proportion $(52.5 \%)$ was observed with a prior malignancy among elderly individuals (>65 years), indicating that elderly patients should receive more attention. Breast, colon and rectum, and uterine cancers were the three most common types of prior malignancies in our study. Breast and uterine cancers are the most common malignancies among females [18]. Studies have reported that women with breast cancer are prone to develop primary ovarian cancer $[19,20]$. Genetic susceptibility and similar exposure factors might be the cause of multiple malignancies in ovarian cancer patients [21, 22]. Patients with breast cancer have achieved prolonged survival time due to 
early detection and improved comprehensive therapies and are more likely to develop a second malignancy with inherited conditions [23]. In addition, less elevated CA-125 levels and smaller ovarian cancer tumour sizes were observed in cancer survivors. This information indicated that those cancer survivors were given more intensive surveillance; therefore, it is necessary to screen for ovarian cancer as a second malignancy among cancer survivors. Moreover, the median interval from the first malignancy to the subsequent ovarian cancer varies by the initial malignancy site. This finding might provide clues for screening different malignancies according to the variations in time intervals [24].

Among the female population, ovarian cancer is one of the most malignant tumours, and the 5-year survival rate for the general population with ovarian cancer is approximately $47 \%[1,25,26]$. In the present study, the 5-year all-cause survival rate of ovarian cancer patients with a prior malignancy was $35.1 \%$, which was much lower than that in patients without prior malignancies (43.2\%) and the general population. Importantly, the multivariate analysis indicated that ovarian cancer patients with a pre-existing malignancy were associated with a more inferior prognosis than those without. This trend might be because patients with prior cancer received less surgery and chemotherapy, and therapies such as surgery and chemotherapy were negatively linked to the survival outcomes in our study. Similar results have also been found in non-Hodgkin lymphoma, stage IV colorectal cancer, lung cancer and prostate cancer [27-30]. Conversely, earlier studies observed opposite results: a history of neoplasm did not result in a worse prognosis [31-33]. Different population sizes and inclusion criteria for study populations (e.g., sex, age, stage, interval time) might contribute to the discrepancy.

To further evaluate the heterogeneous impacts of previous malignancy, we adopted a subgroup survival analysis of ovarian cancer patients stratified by specific prior cancer sites. Lung cancer remains the primary cause of cancer mortality in females according to 2020 cancer statistics [1]. We observed that prior lung cancer was associated with significantly inferior survival in the current study. Consistently, Zhou et al. reported that lung cancer had a detrimental impact on the survival of prostate cancer patients [34]. We speculate that the poor prognosis may be the only reflection of the aggressive biology and high fatality rate of lung cancer [17]. As the third most common cancer [1], colorectal cancer was found to adversely impact all-cause and ovarian

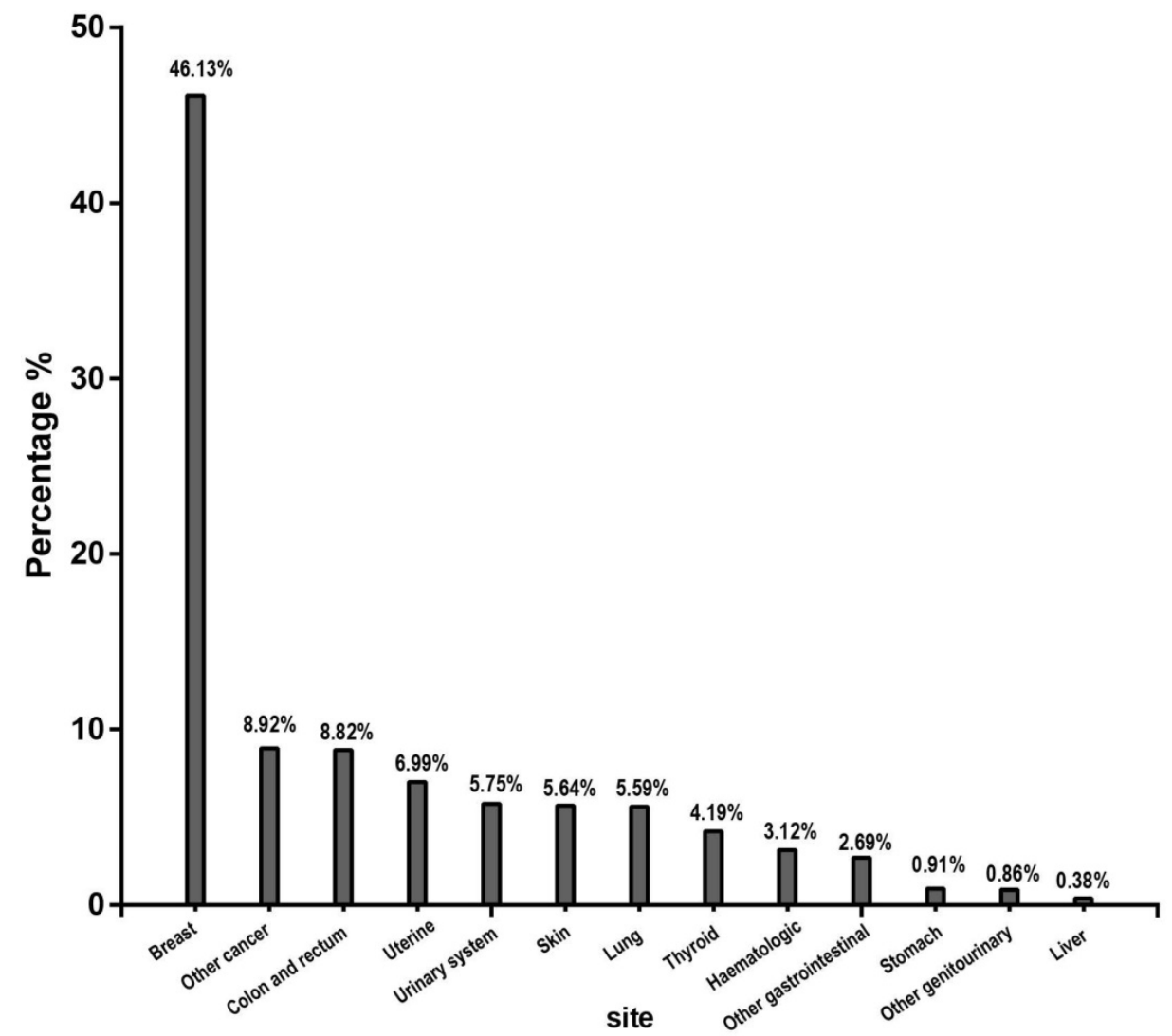

Figure 1. Type distribution of the most common prior cancer for patients diagnosed with ovarian cancer. 
cancer-specific survival in our cohort. A previous study showed that colorectal cancer had a poor survival outcome in patients diagnosed with a previous malignancy [35]. Similarly, survival detriments were also observed in the groups with stomach, urinary system, skin and haematologic cancers.

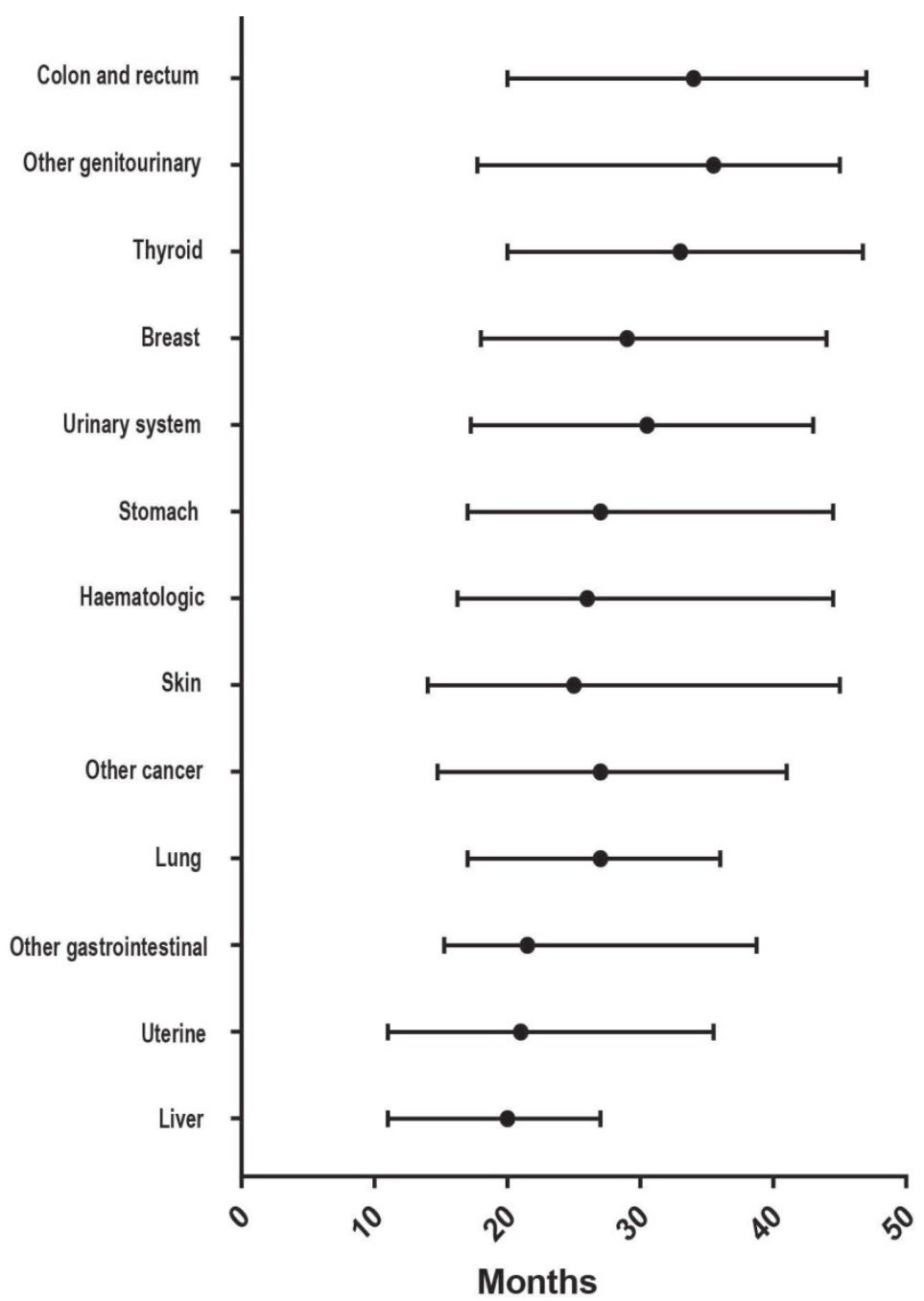

Figure 2. Distribution of the median interval time from prior cancer diagnosis to the subsequent ovarian cancer diagnosis.
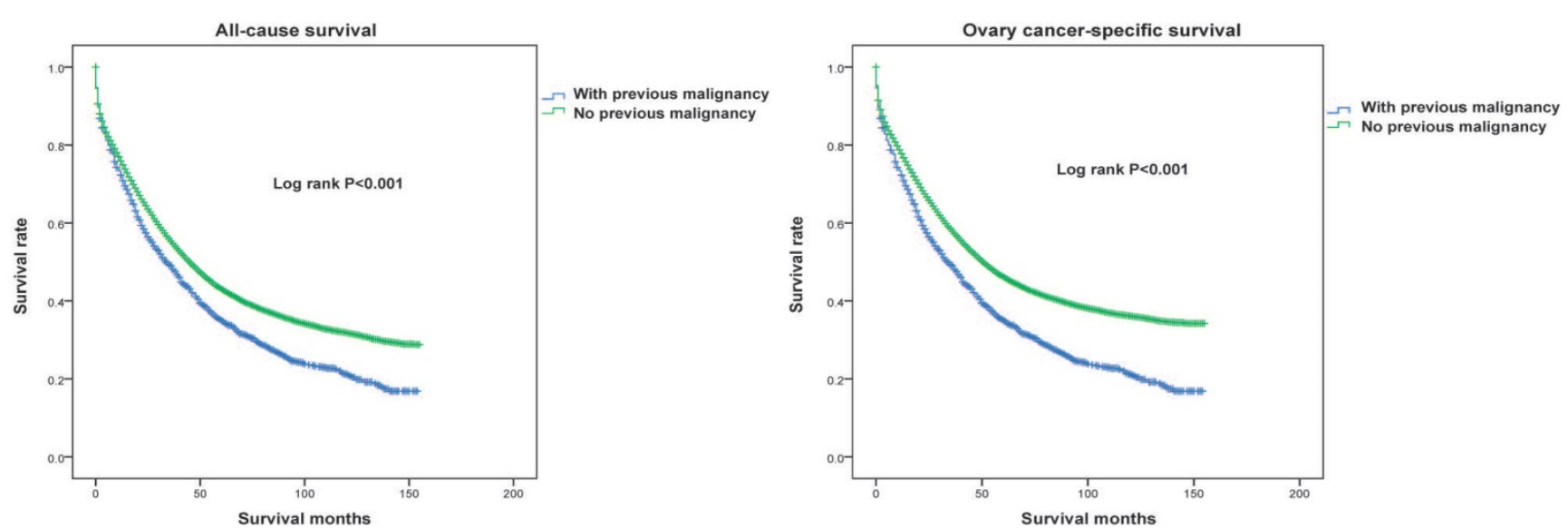

Figure 3. All-caused (left panel) and ovarian cancer-specific (right panel) survival between ovarian cancer patients with and without a prior cancer. All statistical tests were two-sided and $P$ values were estimated and compared based on the log-rank test. 


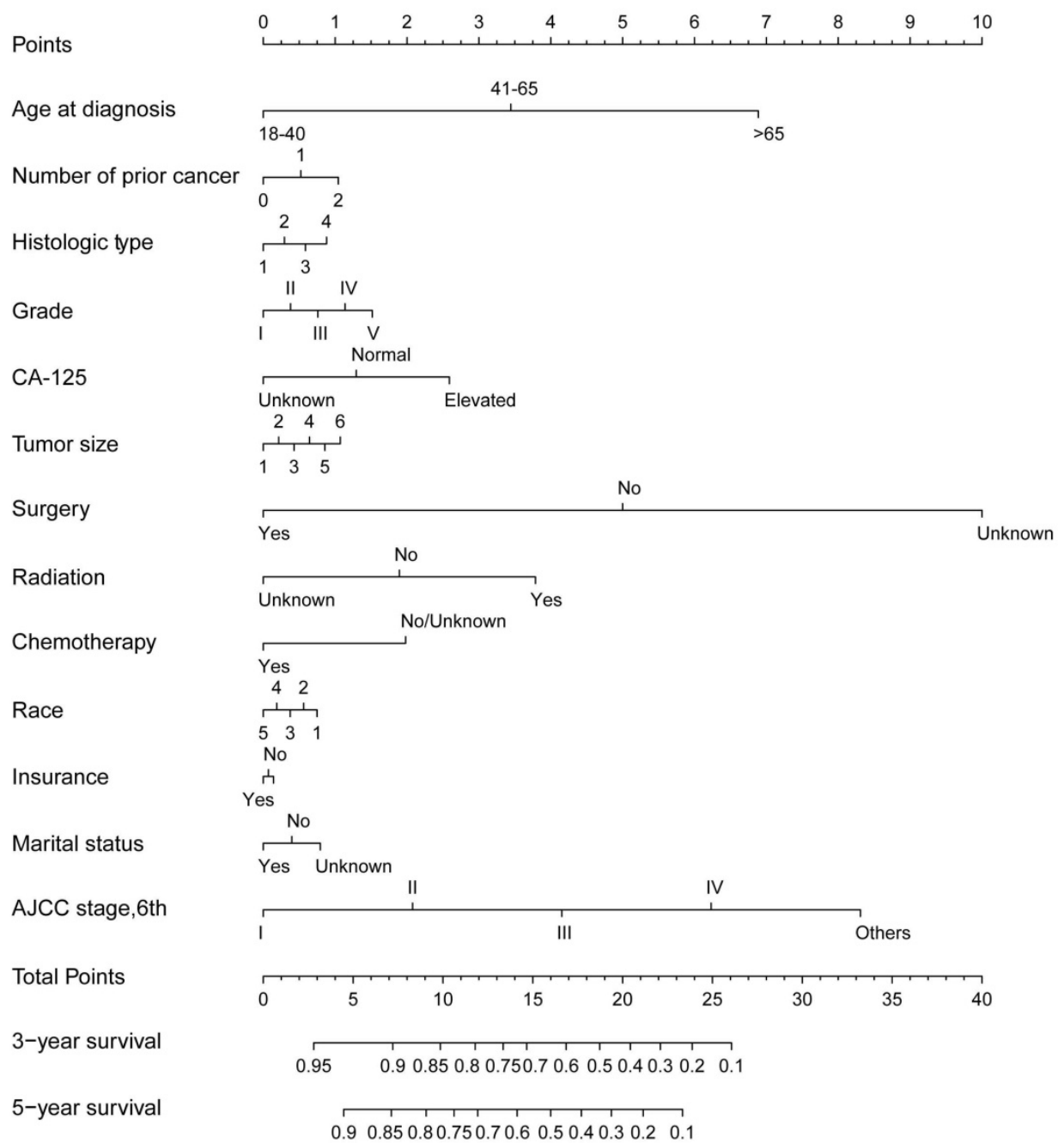

Figure 4. The nomogram for predicting all-caused survival in ovarian cancer patients with and without a prior cancer. Abbreviations: AJCC, American Joint Committee on Cancer.

Table 4. Multivariable Cox regression analysis of all-caused and ovarian cancer-specific survival in patients stratified by previous cancer site

\begin{tabular}{|c|c|c|c|c|}
\hline Characteristics & $\begin{array}{l}\text { All-cause } \\
\text { adjusted HR }\end{array}$ & $\mathbf{P}$ & $\begin{array}{l}\text { Ovarian cancer-specific } \\
\text { adjusted HR }\end{array}$ & $\mathbf{P}$ \\
\hline $\begin{array}{l}\text { Previous cancer } \\
\text { site }\end{array}$ & & $<0.001$ & & $<0.001$ \\
\hline None & Reference & & Reference & \\
\hline Breast & $1.07(0.98,1.16)$ & 0.147 & $1.17(1.08,1.28)$ & $<0.001$ \\
\hline Colon and rectum & $1.69(1.42,2.02)$ & $<0.001$ & $1.85(1.55,2.21)$ & $<0.001$ \\
\hline Uterine & $0.94(0.74,1.18)$ & 0.582 & $1.03(0.82,1.30)$ & 0.794 \\
\hline Urinary system & $1.55(1.24,1.95)$ & $<0.001$ & $1.70(1.36,2.13)$ & $<0.001$ \\
\hline Skin & $1.28(1.00,1.62)$ & 0.046 & $1.40(1.10,1.78)$ & 0.006 \\
\hline Lung & $1.97(1.59,2.44)$ & $<0.001$ & $2.16(1.74,2.68)$ & $<0.001$ \\
\hline Thyroid & $0.70(0.49,0.98)$ & 0.037 & $0.76(0.54,1.08)$ & 0.122 \\
\hline Haematologic & $2.52(1.91,3.32)$ & $<0.001$ & $2.75(2.01,3.62)$ & $<0.001$ \\
\hline $\begin{array}{l}\text { Other } \\
\text { gastrointestinal }\end{array}$ & $1.69(1.22,2.35)$ & 0.002 & $1.85(1.34,2.57)$ & $<0.001$ \\
\hline Stomach & $2.35(1.42,3.90)$ & 0.001 & $2.58(1.56,4.29)$ & $<0.001$ \\
\hline $\begin{array}{l}\text { Other } \\
\text { genitourinary }\end{array}$ & $1.31(0.73,2.36)$ & 0.372 & $1.45(0.80,2.62)$ & 0.218 \\
\hline Liver & $1.65(0.74,3.67)$ & 0.22 & $1.80(0.81,4.01)$ & 0.150 \\
\hline Other cancer & $1.67(1.40,1.99)$ & $<0.001$ & $1.83(1.53,2.18)$ & $<0.001$ \\
\hline
\end{tabular}

In contrast, decreased all-cause mortalities were observed in patients with prior thyroid cancer, indicating that certain types of prior malignancy might exert better effects on survival outcomes in patients with ovarian cancer. Consistent with our investigation, previous studies have reported that ovarian cancer patients with prior uterine cancer have either a favourable prognosis or no difference in prognosis when compared to patients without [36-38]. In general, patients with inert cancers, such as thyroid and uterine cancers, were under more frequent and intensive healthcare, had less exposure to risk factors and received more medical resources and insurance protection [17, 39]. These factors might result in favourable prognostic outcomes for patients with an initial cancer. Additionally, patients with a pre-existing breast cancer faced a worse ovarian cancer-specific survival than did patients without a prior neoplasm. Interestingly, no significant difference was observed in the all-cause survival 
between the two groups. In another study of patients with ovarian cancer following breast cancer, researchers found that individuals with prior breast cancer survived longer than those with ovarian cancer alone [40]. BRCA1/2 mutation is a marker of hereditary breast and ovarian cancers and is related to improved survival among patients [41-44]. However, the effect of the mutant gene on prognostic outcomes remains unknown, as data from BRCA carriers were unavailable in the database. Moreover, a history of liver cancer did not affect the prognosis for either all-cause or ovarian cancer-specific survival, which might be due to the reduction in exposure to risk factors such as smoking and alcohol.

Our study suggested that the inconsistent survival effects of previous malignancies should be considered in clinical trial design and recruitment. In most cancer trials, patients with prior cancer diagnosed within a past 5-year interval are excluded from enrolment $[15,45,46]$. The reasons for the exclusion include the effects on outcomes, unclear adverse effects, tolerance or reduced efficiency of experimental treatments [30]. However, the number of cancer survivors with a second cancer is increasing, and excessively restrictive inclusion criteria would limit the generalizability of the trials [8]. Importantly, some clinical trials of ovarian cancer exclude patients with any previous malignancy, while some of the trials did not [11-13]. Our results indicated that the impacts on the prognostic outcomes of ovarian cancer vary by the different types of prior cancer. Therefore, refinement of the inclusion criteria for patients with prior cancer is of great clinical importance. For instance, prior cancer therapy, rather than a prior cancer diagnosis, can be considered a criterion of exclusion. Clinical management of ovarian cancer with previous malignancies should be adopted in a site-dependent manner. Moreover, factors that might affect treatment tolerance (organ function, genetics and patient status) should be taken into consideration in inclusion or exclusion criteria [39]. These strategies have already been adopted in multiple lung cancer trials $[10,39]$.

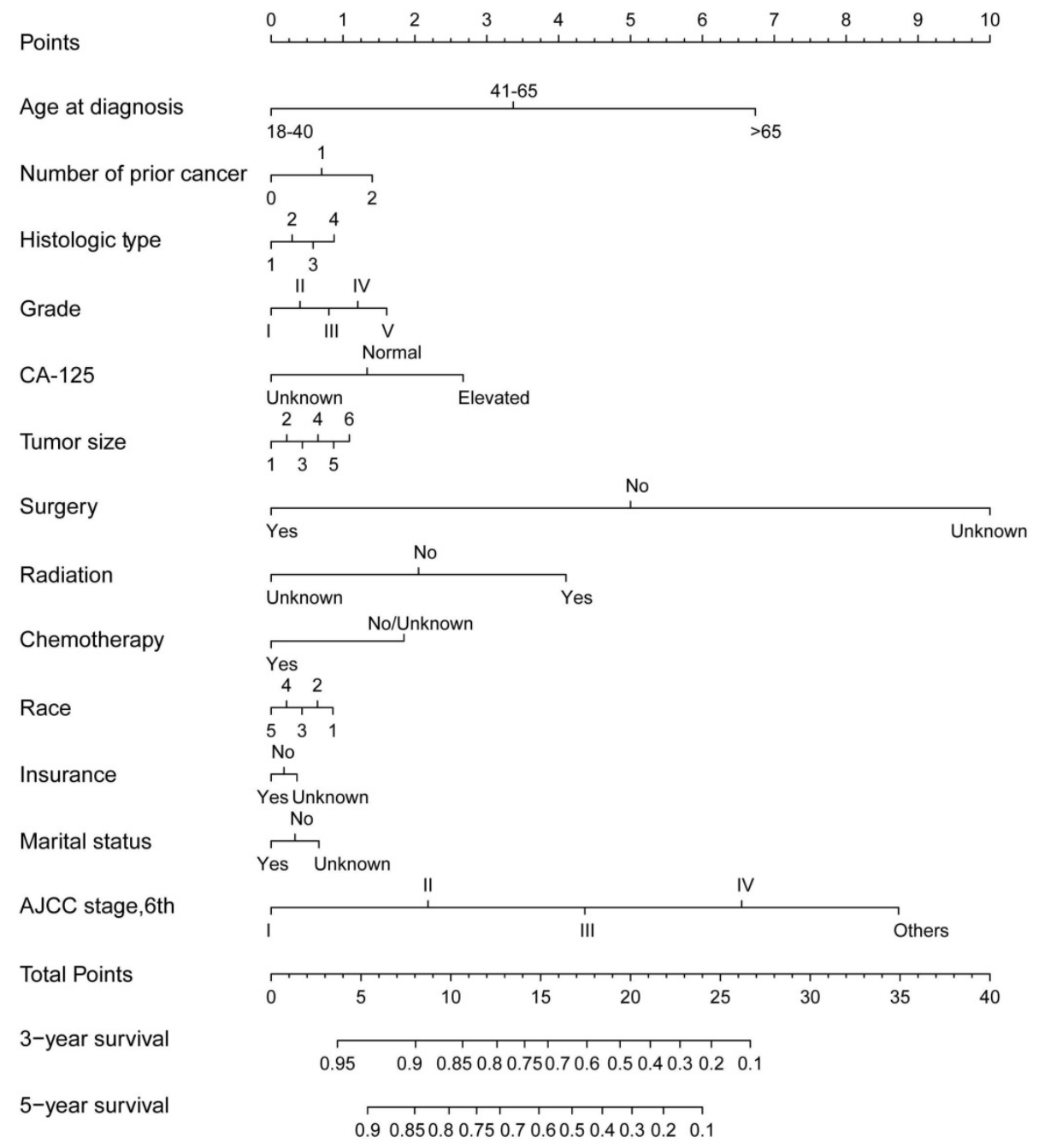

Figure 5. The nomogram for predicting ovarian cancer-specific survival in ovarian cancer patients with and without a prior cancer. Abbreviations: AJCC, American Joint Committee on Cancer. 
There are some limitations in the current study. First, complete information about lifestyle, genetics and environmental factors was not provided in the SEER database. In addition, the database lacked detailed data on complications and treatment, which may affect the survival outcomes of patients. Furthermore, the number of some specific prior cancer sites was too small to accurately conduct a statistical analysis, so they were grouped into other categories. Since this was a retrospective study, an intrinsic selection bias exists regarding patients with advanced malignancy who may not survive long enough to develop ovarian cancer. Last, there was a surveillance bias in that patients with prior cancer tend to be given more intensive surveillance and comprehensive therapies.

\section{Conclusions}

In conclusion, the clinical characteristics of ovarian cancer patients with prior cancer significantly differed from those without prior cancer. A prior cancer had an adverse impact on the survival of patients with ovarian cancer, and the impact on prognostic outcomes varied by the different prior cancer sites. Therefore, the inconsistent survival effects of previous malignancies should be considered in clinical trial design and recruitment.

\section{Supplementary Material}

Supplementary figures.

http://www.jcancer.org/v11p6178s1.pdf

\section{Acknowledgements}

\section{Funding}

This work was supported by the Key Program of the National Natural Science Foundation of China (No. 81790631, 81570512), the National Key Research and Development Program of China (2018YFC2000500), and Natural Science Foundation of Zhejiang Province, China (LQ19H03007).

\section{Author Contributions}

Bian xy and Li lj designed the study, Bian xy, Xia jf, Wang kc and collected and analyzed the data. Bian xy wrote the manuscript. Wang qq, Wu wr and $\mathrm{Li} \mathrm{lj}$ reviewed the manuscript.

\section{Competing Interests}

The authors have declared that no competing interest exists.

\section{References}

1. Siegel RL, Miller KD, Jemal A. Cancer statistics, 2020. CA Cancer J Clin. 2020; 70: 7-30.

2. Siegel R, DeSantis C, Virgo K, Stein K, Mariotto A, Smith T, et al. Cancer treatment and survivorship statistics, 2012. CA Cancer J Clin. 2012; 62: 220-41.
3. Miller KD, Siegel RL, Lin CC, Mariotto AB, Kramer JL, Rowland JH, et al. Cancer treatment and survivorship statistics, 2016. CA Cancer J Clin. 2016; 66: 271-89.

4. Li Z, Wu Q, Song J, Zhang Y, Zhu S, Sun S. Risk of Second Primary Female Genital Malignancies in Women with Breast Cancer: a SEER Analysis. Hormones \& cancer. 2018; 9: 197-204.

5. Zhuang L, Yan X, Meng Z. Second primary malignancy in patients with cholangiocarcinoma: a population-based study. Cancer Manag Res. 2019; 11: 1969-83.

6. Zhang GQ, Wu B, Wang XF, Li JD. Second primary malignancy in patients with esophageal adenocarcinoma and squamous cell carcinoma. Medicine. 2019; 98: 7 .

7. Zhou HQ, Shen JY, Zhang YX, Huang Y, Fang WF, Yang YP, et al. Risk of second primary malignancy after non-small cell lung cancer: a competing risk nomogram based on the SEER database. Ann Transl Med. 2019; 7: 22.

8. Murphy CC, Gerber DE, Pruitt SL. Prevalence of Prior Cancer Among Persons Newly Diagnosed With Cancer: An Initial Report From the Surveillance, Epidemiology, and End Results Program. JAMA oncology. 2018; 4: 832-6.

9. Zhang W, Zhang W, Lin Z, Wang F, Li M, Zhu L, et al. Survival Outcomes of Patients with Primary Breast Cancer Following Primary Ovarian Cancer. Medical Science Monitor. 2019; 25: 3869-79.

10. Gerber DE, Laccetti AL, Xuan L, Halm EA, Pruitt SL. Impact of prior cancer on eligibility for lung cancer clinical trials. Journal of the National Cancer Institute. 2014; 106(11):dju302.

11. Fagotti A, Ferrandina G, Vizzielli G, Fanfani F, Gallotta V, Chiantera V, et al. Phase III randomised clinical trial comparing primary surgery versus neoadjuvant chemotherapy in advanced epithelial ovarian cancer with high tumour load (SCORPION trial): Final analysis of peri-operative outcome. European journal of cancer (Oxford, England : 1990). 2016; 59: 22-33.

12. Oza AM, Cook AD, Pfisterer J, Embleton A, Ledermann JA, Pujade-Lauraine E, et al. Standard chemotherapy with or without bevacizumab for women with newly diagnosed ovarian cancer (ICON7): overall survival results of a phase 3 randomised trial. The Lancet Oncology. 2015; 16: 928-36.

13. Moore K, Colombo N, Scambia G, Kim BG, Oaknin A, Friedlander M, et al. Maintenance Olaparib in Patients with Newly Diagnosed Advanced Ovarian Cancer. The New England journal of medicine. 2018; 379: 2495-505.

14. Laccetti AL, Pruitt SL, Xuan L, Halm EA, Gerber DE. Prior cancer does not adversely affect survival in locally advanced lung cancer: A national SEER-medicare analysis. Lung cancer (Amsterdam, Netherlands). 2016; 98: 106-13.

15. Gerber DE, Pruitt SL, Halm EA. Should criteria for inclusion in cancer clinical trials be expanded? Journal of comparative effectiveness research. 2015; 4: 289-91.

16. Huang X, Zhang B, Zhao J, Sun C, Kong K, Deng L, et al. Increased Risk of Second Primary Cancers Following Diagnosis of Malignant Intraductal Papillary Mucinous Neoplasms of the Pancreas: A Population-Based Study. Front Oncol. 2019; 9: 610.

17. Bian XY, He XK, Yang LY, Wu WR, Li LJ. Prognosis of Hepatocellular Carcinoma Among Cancer Survivors with Other Types of Primary Tumors. Digestive diseases and sciences. 2019; 65(7):2140-2147.

18. Nelson HD, Zakher B, Cantor A, Fu RW, Griffin J, O'Meara ES, et al. Risk Factors for Breast Cancer for Women Aged 40 to 49 Years A Systematic Review and Meta-analysis. Ann Intern Med. 2012; 156: 635-U79.

19. Bergfeldt K, Rydh B, Granath F, Gronberg H, Thalib L, Adami HO, et al. Risk of ovarian cancer in breast-cancer patients with a family history of breast or ovarian cancer: a population-based cohort study. Lancet. 2002; 360: 891-4.

20. Molina-Montes E, Pollan M, Payer T, Molina E, Davila-Arias C, Sanchez MJ. Risk of second primary cancer among women with breast cancer: a population-based study in Granada (Spain). Gynecologic oncology. 2013; 130: 340-5

21. Hiripi E, Lorenzo Bermejo J, Li X, Sundquist J, Hemminki K. Familial association of pancreatic cancer with other malignancies in Swedish families. British journal of cancer. 2009; 101: 1792-7.

22. Klein AP. Genetic susceptibility to pancreatic cancer. Molecular carcinogenesis. 2012; 51: 14-24.

23. Newman B, Millikan RC, King MC. Genetic epidemiology of breast and ovarian cancers. Epidemiologic reviews. 1997; 19: 69-79.

24. He XK, Li Y, Su TT, Lai SC, Wu WR, Chen LY, et al. The impact of a history of cancer on pancreatic ductal adenocarcinoma survival. United European Gastroenterol J. 2018; 6: 888-94.

25. Yeung TL, Leung CS, Yip KP, Au Yeung CL, Wong ST, Mok SC. Cellular and molecular processes in ovarian cancer metastasis. A Review in the Theme: Cell and Molecular Processes in Cancer Metastasis. American journal of physiology Cell physiology. 2015; 309: C444-56.

26. Nasioudis D, Ko EM, Haggerty AF, Giuntoli RL, 2nd, Burger RA, Morgan MA, et al. Isolated distant lymph node metastases in ovarian cancer. Should a new substage be created? Gynecologic oncology reports. 2019; 28: 86-90.

27. Dinh KT, Mahal BA, Ziehr DR, Muralidhar V, Chen YW, Viswanathan VB, et al. Risk of prostate cancer mortality in men with a history of prior cancer. BJU international. 2016; 117: E20-8.

28. Pulte D, Gondos A, Brenner H. Long-term survival of patients diagnosed with non-Hodgkin lymphoma after a previous malignancy. Leukemia \& lymphoma. 2009; 50: 179-86. 
29. Lopez-Encuentra A, Gomez de la Camara A, Rami-Porta R, Duque-Medina JL, de Nicolas JL, Sayas J. Previous tumour as a prognostic factor in stage I non-small cell lung cancer. Thorax. 2007; 62: 386-90.

30. Al-Husseini MJ, Saad AM, Mohamed HH, Alkhayat MA, Sonbol MB, Abdel-Rahmaner O. Impact of prior malignancies on outcome of colorectal cancer; revisiting clinical trial eligibility criteria. BMC cancer. 2019; 19: 9.

31. Pruitt SL, Laccetti AL, Xuan L, Halm EA, Gerber DE. Revisiting a longstanding clinical trial exclusion criterion: impact of prior cancer in early-stage lung cancer. British journal of cancer. 2017; 116: 717-25.

32. Pandurengan RK, Dumont AG, Araujo DM, Ludwig JA, Ravi V, Patel S, et al. Survival of patients with multiple primary malignancies: a study of 783 patients with gastrointestinal stromal tumor. Annals of oncology : official journal of the European Society for Medical Oncology. 2010; 21: 2107-11.

33. He CB, Zhang Y, Cai ZY, Lin XJ. Effect of prior cancer on survival outcomes for patients with pancreatic adenocarcinoma: a propensity score analysis. BMC cancer. 2019; 19: 11.

34. Zhou Y, Guan H, Fu Y, Mao LK, Ge JY, Liu LT, et al. The impact of pre-existing cancer on survival of prostate cancer patients A population-based study. Medicine. 2018; 97: 6.

35. Zhou H, Huang Y, Qiu Z, Zhao H, Fang W, Yang Y, et al. Impact of prior cancer history on the overall survival of patients newly diagnosed with cancer: A pan-cancer analysis of the SEER database. Int J Cancer. 2018; 143: 1569-77.

36. Matsuo K, Machida H, Blake EA, Holman LL, Rimel BJ, Roman LD, et al. Trends and outcomes of women with synchronous endometrial and ovarian cancer. Oncotarget. 2018; 9: 28757-71.

37. Zaino R, Whitney C, Brady MF, DeGeest K, Burger RA, Buller RE. Simultaneously detected endometrial and ovarian carcinomas--a prospective clinicopathologic study of 74 cases: a gynecologic oncology group study. Gynecologic oncology. 2001; 83: 355-62.

38. Soliman PT, Slomovitz BM, Broaddus RR, Sun CC, Oh JC, Eifel PJ, et al. Synchronous primary cancers of the endometrium and ovary: a single institution review of 84 cases. Gynecologic oncology. 2004; 94: 456-62.

39. Laccetti AL, Pruitt SL, Xuan L, Halm EA, Gerber DE. Effect of prior cancer on outcomes in advanced lung cancer: implications for clinical trial eligibility and accrual. Journal of the National Cancer Institute. 2015; 107(4):djv002.

40. Zhang W, Zhang WQ, Lin ZH, Wang F, Li MJ, Zhu LB, et al. Survival Outcomes of Patients with Primary Breast Cancer Following Primary Ovarian Cancer. Medical Science Monitor. 2019; 25: 3869-79.

41. George A, Kaye S, Banerjee S. Delivering widespread BRCA testing and PARP inhibition to patients with ovarian cancer. Nature reviews Clinical oncology. 2017; 14: 284-96.

42. Yang D, Khan S, Sun Y, Hess K, Shmulevich I, Sood AK, et al. Association of BRCA1 and BRCA2 mutations with survival, chemotherapy sensitivity, and gene mutator phenotype in patients with ovarian cancer. Jama. 2011; 306: 1557-65.

43. Alsop K, Fereday S, Meldrum C, deFazio A, Emmanuel C, George J, et al. BRCA mutation frequency and patterns of treatment response in BRCA mutation-positive women with ovarian cancer: a report from the Australian Ovarian Cancer Study Group. Journal of clinical oncology : official journal of the American Society of Clinical Oncology. 2012; 30: 2654-63.

44. Zhong Q, Peng HL, Zhao X, Zhang L, Hwang WT. Effects of BRCA1- and BRCA2-related mutations on ovarian and breast cancer survival: a meta-analysis. Clinical cancer research : an official journal of the American Association for Cancer Research. 2015; 21: 211-20.

45. Zhao GS, Liu Y, Zhang O, Li C, Zhang YW, Ren ZZ, et al. Transarterial chemoembolization combined with Huaier granule for the treatment of primary hepatic carcinoma: Safety and efficacy. Medicine. 2017; 96: e7589.

46. Gandara DR, Kawaguchi T, Crowley J, Moon J, Furuse K, Kawahara M, et al. Japanese-US common-arm analysis of paclitaxel plus carboplatin in advanced non-small-cell lung cancer: a model for assessing population-related pharmacogenomics. Journal of clinical oncology : official journal of the American Society of Clinical Oncology. 2009; 27: 3540-6. 